\title{
Longitudinal investigation on personality traits and mental health relationships: the mediating role of work-family interference and enhancement
}

\author{
Anil Boz Semerci (D) $1 \cdot A, B, C, D, E, F$, Thierry Volery (1D $2 \cdot A, B, C, D, E, F$ \\ 1: Hacettepe University, Ankara, Turkey \\ 2: University of Western Australia, Perth, Australia
}

\section{BACKGROUND}

The purpose of this paper is to investigate the impact of the Big Five personality traits on work-family interference/ enhancement and mental health using a three-wave longitudinal design.

\section{PARTICIPANTS AND PROCEDURE}

The paper draws on a sample $(N=886)$ from the Household, Income and Labor Dynamics in Australia survey. Structural equation modeling was used to examine the measures of the variables and assess their associations across three time periods.

\section{RESULTS}

The results indicate that conscientiousness and emotional stability are the personality traits that are associated with work-to-family enhancement over time. In addition, workto-family enhancement is a mediator between emotional stability and mental health. Overall, there exists a positive reciprocal relationship between work-to-family enhancement and mental health throughout the three waves.
CONCLUSIONS

This study showed that there is a bidirectional positive link between work-to-family enhancement and mental health. The findings suggest that organizations will benefit not only from developing interventions to enrich employees' work skills, behaviors/attitudes but also from promoting their mental health and emotional stability. This study is the first to confirm the partial mediation role of workto-family enhancement between emotional stability and mental health, and bidirectional relations of work-to-family enhancement and mental health. Moreover, the longitudinal design of this study overcomes the limitations of prior cross-sectional studies in evaluating the relationships of constructs.

\section{KEY WORDS}

personality; mental health; work-to-family interference and enhancement

Corresponding Author - Anil Boz Semerci, Ph.D., Hacettepe University, Beytepe Campus, 06800 Ankara, Turkey, e-mail: annilboz@gmail.com

Authors' contribution - A: Study design · B: Data collection · C: Statistical analysis · D: Data interpretation ·

E: Manuscript preparation · F: Literature search · G: Funds collection

TO CITE THIS ARTICLE - Boz Semerci, A., \& Volery, T. (2019). Longitudinal investigation on personality traits and mental health relationships: the mediating role of work-family interference and enhancement. Current Issues in Personality Psychology, 7(3), 173-188.

RECEIVED 15.03.2019 • REVIEWED 24.09.2019 • ACCEPTED 29.09.2019 • PUBLISHED 30.09.2019 


\section{BACKGROUND}

Mental health is fundamental to our collective and individual ability as humans to think, emote, interact with each other, earn a living and lead a fulfilling life. That includes the ability to study, work or pursue leisure interests, and to make day-to-day personal decisions about educational, employment, family or other choices (WHO, 2006). The importance of mental health stems from the nature of human capital and is an integral component of human health. Today, mental health disorders are becoming more prevalent all over the world and may have a damaging effect on both individuals and families, and far-reaching effects on society as a whole. The World Health Organization (WHO) estimates that some 450 million people worldwide suffer from mental health disorders and many more have lesser mental health problems (WHO, 2013).

Personality is one of the most important predictors of mental health and personality traits are considered both a protective and promoting factor of mental illnesses (Tan, 2007). Understanding individuals' personality can shed some light on their behaviors in given circumstances: their preference, their motivations and wishes, and, ultimately, their wellbeing. In the same vein, there is strong evidence that personality is related to vocational behavior (Cheng \& Furnham, 2001; Judge, Heller, \& Mount, 2002; Matzler \& Renzl, 2007) and career success (Fang et al., 2015) while controlling for general mental ability (Judge, Higgins, Thoresen, \& Barrick, 1999). Although there are many studies on personality and mental health, the previously established associations are still weaker than expected (Kotov, Gamez, Schmidt, \& Watson, 2010). In addition, little attention has been paid to the question of how personality variables relate to mental health longitudinally.

The work-family interface represents another debated issue in the mental health literature. Work and family are two equally important domains in human life (Casper, Harris, Taylor-Bianco, \& Wayne, 2011). Parents in paid work try to reconcile two key aspirations: commitment to caring for their family and participation in the labor market. However, today's 24/7 service-on-demand and hyper-connected society requires workers to expand their effort and be flexible, even at the risk of not fulfilling their family roles and affecting their well-being. Indeed, family, work, and health are often mentioned by adults as the most important things in their lives (Rantanen, Pulkkinen, \& Kinnunen, 2005).

The objective of this study is to investigate the impact of personality traits and the work-family interface on mental health. More specifically, we consider the influence of the Big Five personality variables on mental health of individuals who are working and have parenting responsibilities. As reported in the work-family methodological review by Casper, Eby,
Bordeaux, Lockwood, and Lambert (2007), many cross-sectional studies have been conducted in the work-family research field, but longitudinal studies are as yet very rare. To this end, responding to the call of Wayne, Musisca, and Fleeson (2004) for longitudinal research, we first investigate the simultaneous, longitudinal role of personality on work-to-family interference (WFI) and work-to-family enhancement (WFE). Second, we test the WFI and WFE longitudinal effects on mental health. Thereafter, we analyze whether there is any longitudinal mediating impact of these work-family experiences or not. This mediating impact is important for deepening our understanding of whether individuals' personality traits reduce or enhance their mental health via a balanced work-family approach over time.

This study contributes to the field of psychology and vocational behavior in three ways. First, by focusing on the direct and indirect paths, we expand the association between personality and mental health. At a direct level, we aim to determine whether personality and mental health are related by showing that they rely on common substrates. At the indirect level, we seek to understand whether personality traits are also seen to promote (or lower) mental health. Second, this study sheds some light on the association between work and mental health. Although many studies have established correlations between mental health and work-related factors, they are generally cross-sectional in nature and therefore fail to capture long-term effects (Wayne et al., 2004). Beside this methodological development, past research has traditionally focused on the impact of unemployment and the erosion of work life on mental health or vice versa (Murphy \& Athanasou, 1999; Breslin \& Mustard, 2003). There is a need to consider work's impact on individuals' family lives and their interaction with individual mental health in the development of behavior. Third, this study complements past cross-sectional research, which attempted to evaluate the impact of the Big Five on work-to-family interference (Kinnunen, Vermulst, Gerris, \& Makikangas, 2003; Schieman \& Glavin, 2011) by adding work-to-family enhancement as a positive spillover. Positive spillover refers to the fact that the experiences in one domain (work) provide beneficial effects to another domain (family). The following three sections represent the discussions related to personality traits, WFI, WFE and mental health linkages. This is followed by a description of our three-wave longitudinal study and the presentation of the results.

\section{THE IMPACT OF PERSONALITY TRAITS ON MENTAL HEALTH}

The past two decades have seen a considerable evolution of the field of mental health and related disciplines, including psychology. While most of the 
early research focused on negative psychology topics (anxiety, depression and so on), positive psychological terms (positive experiences and relationships, enduring psychological traits) have received growing attention since the 1980s (Shirazi, Khan, \& Ansari, 2013). This latter stream of research investigates and promotes realistic ways of fostering greater wellbeing in individuals and communities. Similarly, the World Health Organization defined mental health as "a state of well-being in which the individual realizes his or her own abilities, can cope with the normal stresses of life, can work productively and fruitfully, and is able to make a contribution to his or her community" (WHO, 2005; p. 2). Mental health has often been considered as synonymous with 'psychological health' or 'psychological well-being'.

Past research underlined that personality traits are key antecedents of mental health (Furnham \& Cheng, 1999; Goodwin \& Friedman, 2006; Haslam, Whelan, \& Bastian, 2009). Schacter, Gilbert, and Wegner (2009, p. 468) defined personality "as an individual's characteristic style of behaving, thinking, and feeling." Other scholars defined personality as the totality of character attributes and behavioral traits of a person (Shirazi et al., 2013). The personality characteristics are generally summarized in terms of the "Big Five" personality dimensions: agreeableness, conscientiousness, extraversion, emotional stability, and openness to experience (Barrick \& Mount, 1991). The model provides a comprehensive framework for describing personality and has great utility by integrating and systematizing several concepts and measurements (McCrae \& Costa, 2008; Goldberg, 1993).

In conservation of resource theory personal characteristics are considered as the limited individual resources and as factors influencing individuals' wellbeing. Conservation of resource theory (COR) developed by Hobfoll (1989) posits that individuals possess some resources, which can be broadly defined as "objects, personal characteristics, conditions, or energies that are valued by the individual" (Hobfoll, 1989). When these resources are threatened or lost, this affects people's physical and psychological health. Personality traits may play a role by exposing people to greater loss events and decreasing their ability to recover from losses. For example, neuroticism shows individuals' balance in terms of their emotions and is considered to be associated with vulnerability to resource losses and stress. On the other hand, some personality traits such as conscientiousness enable people to cope with stressful situations and help in resource investment. Costa and McCrae (1980) also reported the positive effect of extraversion and negative impact of neuroticism on subjective wellbeing. Therefore, the interactions of personality characteristics and mental health should be examined in detail.

Extraversion refers to the degree of sociability or withdrawal that a person tends to exhibit. Extraverts are typically assertive, dominant, energetic, active, talkative, and optimistic. Extraversion tends to correlate with pleasant emotions and is characterized by positive evaluations of life in general and career in particular (Clark \& Watson, 1991) that lead to better mental health.

There is a broad consensus in the literature that extraversion is closely and positively related to mental health (Argyle \& Lu, 1990; Furnham \& Cheng, 1999) and to subjective wellbeing. In this respect, Brebner, Donaldson, Kirby, and Ward (1995) found that scores in extraversion and neuroticism accounted for $42 \%$ of the variance in predicting happiness.

Agreeableness is associated with trust, helpfulness, cooperation, forgiveness, kindness and sympathy (McCrae \& Costa, 1991). A high level of agreeableness characterizes cooperative individuals and a preference for interpersonal relationships. Conversely, someone at the low end of the dimension can be described as self-centered and hard-bargaining. The orientation toward others and being altruistic facilitates the development of social relationships, the capacity to share problems, and to be more relaxed - all of which result in better mental health (DeNeve \& Cooper, 1998; Haslam et al., 2009; McCrae \& Costa, 1991).

Conscientiousness contains two components. The first component reflects dependability. Conscientious individuals are careful, thorough, responsible, and organized (Barrick \& Mount, 1991). The second component underpins volitional variables, suggesting that conscientious individuals are strong-willed, determined, and persistent (McCrae \& John, 1992). Careful planning, effective organization and efficient time management may allow a person to accomplish more in the time available and reduce stress and strain (Wayne et al., 2004).

Given the importance of goal strivings in determining mental health (DeNeve \& Cooper, 1998), conscientious individuals appear to be orientated towards life situations that are beneficial for wellbeing (McCrae \& Costa, 1991). They set themselves higher goals, have high levels of motivation and are more likely to be able to function effectively in society and to achieve their goals (Judge \& Ilies, 2002). There is also empirical evidence that a higher level in conscientiousness significantly decreases the probability of mental disorders (Goodwin \& Friedman, 2006).

Emotional stability is also frequently referred to its converse, neuroticism. Emotionally stable individuals are characterized as usually calm, even-tempered, relaxed and able to face stressful situations without becoming upset. As such, they can manage day-to-day performance pressure, remain optimistic, and generally maintain positive working relationships with coworkers (Hurtz \& Donovan, 2000). Conversely, individuals with a low level of emotional stability tend to experience a number of negative emotions including anxiety, anger, and vulnerability (Berkowitz, 1990). 
Emotional stability is a trait highly relevant to adjustment, and can be considered a major feature in the process of coping with stressors. Individuals low in emotional stability are more likely to use ineffective mechanisms of coping with stress, and be less capable of tasks such as solving problems or avoiding feelings of distress (McCrae \& Costa, 1991). It also indicates a tendency to have unrealistic ideas and inability to control urges, and is negatively associated with mental health (Feldt, Metsapelto, Kinnunen, \& Pulkkinen, 2007).

Together with extraversion, emotional stability is one of the most prevalent personality dimensions in mental health literature (Watson \& Clark, 1992). Over the past decades, this variable emerged as one of the best predictors of wellbeing (Costa \& McCrae, 1980; DeNeve \& Cooper, 1998).

Openness to experience is characterized by creativity, imaginativeness, curiosity, sensitivity, originality and a need for variety (Barrick \& Mount, 1991; McCrae \& John, 1992). Individuals scoring a high level of openness to experience are unconventional, accepting change, creative, curious and question authority (Costa, McCrea, \& Dye, 1991). Open-minded people have strong tendencies to seek out unfamiliar situations that allow for greater access to new experiences and perspectives. They are willing to entertain novel ideas and unconventional values, and they experience both positive and negative emotions more keenly than closed individuals.

Individuals with a high level of openness can better tolerate ambiguity, relax psychologically, and are thus less likely to feel distress when facing uncertain situations in their life (Roccas, Sagiv, Schwartz, $\&$ Knafo, 2002). Open individuals with wide interests and curiosity are likely to make sense out of situations and events in their surroundings and feel that new situations are worthy of engagement. High scores on openness to experience translate into the belief that the world is comprehensible, manageable, and meaningful (Feldt et al., 2007), which in turn promotes better mental health.

\section{IMPACTS OF PERSONALITY TRAITS ON WFI AND WFE}

Recent studies indicated that personality characteristics play not only incentive but also preventive roles in individuals' wellbeing. Allen, Herst, Bruck, and Sutton (2000) reported that while positive traits protect individuals from role conflicts and promote better wellbeing, negative traits play an encouraging role for conflict and stress. Extraversion predisposes people to experience positive affects (Watson \& Clark, 1992), to engage in coping strategies and also be social (Watson \& Hubbard, 1996). As a result of positive evaluations of life, individuals with high extraversion might be less inclined to perceive simultaneous work and family demands as problematic. Because of their energetic, active characteristics and social network, these individuals might have more control over the work and family demands in their lives (Rantanen et al., 2005). In the same way, people who are open to experience are imaginative, curious, and open-minded. This helps them in finding new ways to balance their work and family lives, and consequently, to be protected from WFI (Kossek, Noe, \& DeMarr, 1999) and to improve their mental health.

Agreeable individuals promote interpersonal bonds and social success (McCrae \& Costa, 1991), view their experience in positive terms (Watson \& Hubbard, 1996) and are compassionate and cooperative, which leads to mutual social support. The stronger social support enjoyed by agreeable individuals is likely to prevent work-family conflicts, as these individuals experience fewer difficulties in combining work and family roles.

Conscientious individuals promote effective accomplishment of daily tasks and success in work (McCrae \& Costa, 1991). Their effectiveness, organizational skills, and orderliness may serve as a personal harness to minimize simultaneous demands from work and family (Rantanen et al., 2005). Conscientiousness is also related to lower sensitivity to stressful situations and to active problem solving (Vollrath \& Torgersen, 2000). Consequently, both agreeableness and conscientiousness can be assumed to have positive effects on work-family balance.

Conversely, neuroticism has been identified as a risk factor that is likely to increase WFI (Rantanen et al., 2005). Individuals low in emotional stability are less able to use coping strategies to deal with stress and to balance work and family demands, which leads to higher WFI and increases mental health burdens (Brebner, 2001; Penley \& Tomaka, 2002). Individuals who are emotionally stable tend to see similar stressful situations as a challenge in which they can respond, remaining calm, relaxed and optimistic. As a result this may serve as a promoting factor for work-to-family enhancement and mental health.

Overall, high scores on agreeableness, conscientiousness, emotional stability, extraversion and openness to experience are consistently related to adaptive coping strategies such as planning and focusing on the task at hand, reinterpreting the stressful situation in a positive way, and seeking social support (Penley \& Tomaka, 2002; Pittenger, 2004). The coping strategies in a situation where work demands interfere with family life usually require reduction of the conflict and promotion of work-to-family enhancement, in order to decrease stress. Based on all these theoretical and empirical backgrounds related to each personality traits, we proposed that:

Hypothesis 1: Personality traits (extraversion, agreeableness, conscientiousness, emotional stability 
and openness to experience) have a cross-lagged impact on WFE and WFI, which suggests that employees who are extraverted, agreeable, conscientious, emotionally stable and open to experience subsequently perceive low WFI and high WFE.

\section{THE MEDIATING EFFECT OF WFI AND WFE}

Today, men, and increasingly women, spend a significant part of their life in paid work. While work is at the core of contemporary life, family remains equally important for most people. Pursuing a 'dual career' as a jobholder and a parent can lead to both conflict and enhancement between these roles.

Given the increasing prevalence of dual-breadwinner families, single working parents, and the growing pressure in the workplace, most of the initial research focused on the negative spillovers between work and family domains, where demands from work and family are not always compatible (Greenhaus \& Buetell, 1985; Mesmer-Magnus \& Viswesvaran, 2005). Workfamily interference (or conflict) typically represents an impediment to successfully meeting family-related demands and responsibilities (Frone, Russell, \& Cooper, 1997). It may undermine a person's ability to construct and maintain a positive parental image and may result in missing out on rewarding aspects of being a parent, or present obstacles to being a good parent.

A substantial body of research has shown the negative impact of work-family interference on mental health (Frone, Russell, \& Cooper, 1992; Losoncz \& Bortoiotto, 2009). Resource drain theory assumes that the multiple demands of work and family and participation of multiple roles are detrimental to the individual and invoke stress, resulting in emotional strain (Edwards \& Rothbard, 2000). Individuals who struggle to carry out their work and family roles display reduced mental wellbeing and life satisfaction. One of the most consistent findings in the literature is the strong correlation between work-family interference and stress, depression and stress-related outcomes including psychological strain, anxiety, depression, somatic complaints, elevated blood pressure, and alcohol abuse (Allen et al., 2000; Odle-Dusseau, Britt, \& Bobko, 2012). Individuals' job, family and life satisfaction levels are also found to be negatively associated with work-family interference in some crosssectional (Frye \& Breaugh, 2004) and longitudinal studies (Cho \& Tay, 2016).

More recently researchers have started to consider the positive aspects of the work-family relationship, which is generally called enhancement (Casper, De Hauw, \& Wayne, 2013). Work-family enhancement suggests that the participation in multiple roles and a well-balanced role system, which incorporates all roles (i.e., marital, parental and work roles), provide a greater number of opportunities and resources to enhance individual growth and better functioning (Grzywacz \& Marks, 2000). In addition, work may enrich individuals' skills, behaviors and attitudes and promote positive moods that are useful for parenting roles (Grzywacz, 2000). Work-to-family enhancement (or facilitation) therefore results in higher levels of mental health (Kinnunen, Feldt, Geurts, \& Pulkkinnen, 2006; McNall, Nicklin, \& Masuda, 2010).

In this context, personality is one of the most important individual-related variables in work-family linkages (Baltes, Zhdanova, \& Clark, 2011). Personality traits which enable employees to use their time more efficiently, to engage in roles with more energy, and to perceive less stress lead to a reduction of work-family conflict (Wayne et al., 2004) and better mental health. Personality traits have been shown to not only influence the individuals' interpretation of a situation but also shape the environments in a variety of life domains including both WFI and WFE. The impact of personality is distinct for interference and enhancement. More specifically, it is anticipated that the presence of high scores on each personality characteristic will decrease WFI and, simultaneously, increase WFE. Based on this literature we proposed the hypotheses below.

Hypothesis 2a: WFE has a longitudinal mediating role between personality traits and mental health, which suggests that employees who are extraverted, agreeable, conscientious, emotionally stable and open to experience subsequently experience high workfamily enhancement and in turn better mental health.

Hypothesis 2b: WFI has a longitudinal mediating role between personality traits and mental health, which suggests that employees who are extraverted, agreeable, conscientious, emotionally stable and open to experience subsequently perceive low work-tofamily interference and in turn better mental health.

\section{PARTICIPANTS AND PROCEDURE}

\section{PARTICIPANTS}

This study draws on the Household, Income and Labour Dynamics in Australia (HILDA) survey. HILDA is a nationally representative longitudinal household survey conducted by the Australian government. It investigates life in Australia, focusing on income, the labour market, and family dynamics. The HILDA project has been approved by the Human Research Ethics Committee of the University of Melbourne. The survey was initiated in 2001, and the wave 1 panel consisted of 7,682 households and 19,914 individuals. The survey used four questionnaires, which are a household form, a household questionnaire, a person questionnaire for all household members aged 15 years and over, and a self-completion questionnaire. All 
variables' data used in this study are collected with a self-completion questionnaire. The reference population was all members of private dwellings in Australia, with some exceptions. To ensure that all members of the in-scope population have the same probability of selection, dwellings that were not primary places of residence (for example, holiday homes) were also excluded. The households were selected using a multi-staged approach. First, a sample of 488 Census Collection Districts (CDs) were selected from across Australia. Second, within each of these CDs, a sample of 22 to 34 dwellings was selected, depending on the expected response and occupancy rates of the area. The selections were made after all dwellings within each of the CDs were fully listed. Finally, within each dwelling, up to three households were selected to be part of the sample (Goode \& Watson, 2007).

The constraints related to availability of all variables in each wave and appropriateness of time lags led us to use wave 5 (time 1), 9 (time 2) and 11 (time 3) in this study. Although there is not any clear guideline for deciding time lags of longitudinal studies, two years would be appropriate for our research model. Rantanen et al. (2005) reported that studies that are related to work-family balance and have a time lag more than one year are rare in the literature. They also stated that the stability and reciprocal relationships with antecedent and consequence variables of work-family balance would be indicated better in longitudinal studies with longer than one-year time periods. On the other hand, Frone and colleagues (1997) suggested that the effects of work-to-family conflict might occur in shorter time periods than four years. Therefore, two-year time lags used in this study would be appropriate to indicate a mediator role between personality characteristics and mental health of individuals.

From these three waves, we selected the adults who were employed and had parenting responsibilities (with no distinction of parenting of adult or minor children). This led to a sample of 866 participants across the three waves. In the retained sample, $57.5 \%$ of the respondents were male and $42.5 \%$ were female. The average age was 40.5 years. The vast majority of the respondents $(85.2 \%)$ were legally married or in a de facto relationship, and $14.8 \%$ were single. The respondents' education level varied: $18.9 \%$ had a graduate and postgraduate degree, $30 \%$ had a bachelor degree and $51.1 \%$ had completed 12 years of formal education with no tertiary education.

\section{MEASURES}

Personality variables. The Big Five Personality Inventory, which is an old but practical and widely used tool, consists of 36 items derived from Saucier's (1994) set of adjectives. Participants were asked to rate how well each of the adjectives describes them using a 7-point scale from 1 (does not describe me at all) to 7 (describes me very well). To identify the number of underlying dimensions of personality, principal component analysis with varimax rotation was performed. Varimax rotation is one of the most popular rotation methods that is used to maximize shared variance among items which leads them to be associated with one or a small number of factors (Abdi, 2003). Internal consistency was assessed using Cronbach's $\alpha$. Reliabilities for each factor were good and within the typical range of previous studies that have drawn on HILDA data (Losoncz, 2009): agreeableness (sympathetic, kind, cooperative, warm; $\alpha=.79$ ); conscientiousness (orderly, systematic, inefficient ${ }^{*}$, sloppy ${ }^{*}$, disorganized ${ }^{*}$, efficient; $\alpha=.79$ ); emotional stability (envious ${ }^{*}$, moody $^{*}$, touchy ${ }^{*}$, jealous $^{*}$, temperamental ${ }^{*}$, fretful ${ }^{*} ; \alpha=.79$ ); extraversion (talkative, bashful*, quiet*, extroverted, shy*, lively; $\alpha=.78$ ) and openness to experience (deep, philosophical, creative, intellectual, complex, imaginative; $\alpha=.74)$. The adjectives with an asterisk are reverse scored. Scale scores were created by computing the mean of the items for a given trait, such that higher scores meant higher prevalence of the trait.

Mental health. In order to measure the individuals' mental health, we used the 'mental health' component of the Short Form 36 (SF-36) measure. The SF-36 health survey is an internationally recognized diagnostic tool for assessing functional health status and well-being (Frijters, Johnston, \& Shields, 2014). The mental health scale comprises nine items which include feeling "full of life, nervous*, down in the dumps*, lot of energy, peaceful, happy, worn out*, tired $^{*}$ (the adjectives with an asterisk are reverse scored). The participants were asked to rate the statements using a 6-point scale from 1 (all of the time) to 6 (none of the time). The internal reliability was very good (Cronbach's $\alpha=.89$ ).

Work-to-family interference and work-to-family enhancement. The effect of work on family was measured using the work-family strains and gains scale from Marshall and Barnett (1993). Work-to-family interference (Cronbach's $\alpha=.86$ ) was measured with four items on a Likert scale from 1 (strongly disagree) to 7 (strongly agree). Work-family enhancement (Cronbach's $\alpha=.80$ ) was measured with another four items from the same scale. An example item for work-to-family interference was "Working leaves me with too little time or energy to be the kind of parent I want to be"; for work-to-family enhancement: "The fact that I am working makes me a better parent".

\section{ANALYSIS}

Prior to analyzing the structural models, measurement models and measurement equivalences were tested with a confirmatory factor analysis (CFA). First, the measurement models were run with the 
CFA maximum likelihood estimator and the goodness of fit was checked for each of the three waves. Second, the measurement invariance over time was tested by checking chi square differences between two alternative models. As suggested by Cole and Maxwell (2003), providing measurement invariance is crucial before conducting any structural comparisons over time. Since obtaining full measurement invariance is regarded as difficult, partial measurement invariance, which means metric invariance, is considered sufficient before comparisons of structural models (Byrne, Shavelson, \& Muthén, 1989). To do this, two alternative models were compared with each other. The first model (the unrestricted or autoregressive model) included freely estimated parameters across all three time points, whereas the second model (metric invariance model) contained equal factor loadings within constructs across all the waves. After testing whether the measurement model was invariant over time, the variables were composed by taking the average scores of items that emerged from the CFA. Descriptives and correlation scores are shown in Table 1. Also, to examine the differences within factors regarding time effects, analysis of variance (ANOVA) was conducted. The ANOVA results are presented in the next section.

To test the hypotheses, longitudinal models verifying the paths (within and between constructs) and parameter restrictions were generated and compared. First, a base model (also called a stability or autoregressive model) was computed. This model suggests stability in the within-construct relationship over time. Consequently, in stability model 1, the parameter estimates were allowed to be freely estimated, whereas in stability model 2 , within construct paths in and between time 1, 2 and 3 were constrained to be equal. In a second step, causality models (also referred to as forward unidirectional or forward cross-lagged) were created. In the causality models, paths from personality dimensions at time 1 to WFI and WFE at time 2, from WFI and WFE at time 1 to mental health at time 2, from personality dimensions at time 2 to WFI and WFE at time 3 and from WFI and WFE at time 2 to mental health at time 3 were included. Also, in order to test the direct effect of personality dimensions on mental health, paths from personality dimensions at time 1 to mental health at time 2 and from personality dimensions at time 2 to mental health at time 3 were included. Third, reverse causality (reverse unidirectional or reverse cross-lagged) model 1 and 2, having the same paths as in the causality models but in the reverse direction (from mental health to WFI and WFE), were formed. Lastly, a reciprocal (bidirectional) model that includes all paths from causality and from reversed models was generated. Consistent with stability models, causality, reverse causality and reciprocal models with number 1 are unrestricted (freely estimated parameters), whereas models with number 2 include construct equivalence for paths from time 1 to time 2 and from time 2 to time 3 . All aforementioned models can be seen in Figure 1.

When examining chi square differences between the restricted and unrestricted versions of the same model (e.g., causality model 2 vs causality model 1 ), the more restricted of the two models being compared should not result in a significant worsening in the model fit $(p>.05)$ for it to be retained. When comparing different models to one another (e.g., causality model 2 versus stability model 2 ), the chi square differences should be significant $(p<.05)$ in order to retain the model. The analysis was conducted with SPSS and AMOS (version 23) statistical software packages.

\section{RESULTS}

\section{LONGITUDINAL MEASUREMENT INVARIANCE}

In measurement models of each wave, goodness of fit indices (at time $1 \chi^{2} / d f=1.64, \mathrm{CFI}=0.95, \mathrm{SRMR}=0.05$, RMSEA $=0.05$; at time $2 \chi^{2} / d f=1.72$, CFI $=0.95$, SRMR $=0.05$, RMSEA $=0.06$ and at time $3 \chi^{2} / d f=1.88$, $\mathrm{CFI}=0.95, \mathrm{SRMR}=0.06$, RMSEA $=0.06$ ) suggested an acceptable fit. The criteria for acceptable fit indices were taken from $\mathrm{Hu}$ and Bentler (1999). The items loaded significantly on their underlying factors with loadings above 0.40 .

In testing the longitudinal measurement invariance, model fit of unrestricted and restricted (metric invariance) models was compared. The findings revealed that chi square differences between these models were not significant $\left(\Delta \chi^{2}=12.8, p=.512\right)$, which confirms metric invariance over time.

\section{DESCRIPTIVES, CORRELATIONS AND ANOVA}

After obtaining partial measurement invariance across the times, the composite variables were obtained by taking the average of the related items. The time effects on each of the eight variables were also tested by one-way ANOVA. Extraversion $[F(2,2655)=0.38$, $p=.683]$, conscientiousness $[F(2,2655)=2.48, p=.084]$, emotional stability $[F(2,2655)=2.65, p=.077]$, openness to experience $[F(2,2655)=1.90, p=.149]$, WFI $[F(2,2655)=2.74, p=.118]$, WFE $[F(2,2655)=2.67$, $p=.104]$ and mental health $[F(2,2655)=1.96, p=.146]$ did not show significant differences over time. Agreeableness had significant time effects $[F(2,2655)=6.24$, $p=.002]$. The post hoc comparisons (Bonferroni) revealed that agreeableness mean score at time 3 is significantly different from the scores at time 1 and time 2. This significant time effect implies that participants' agreeableness level increased at time 3 compared with time 1 and time 2 . 


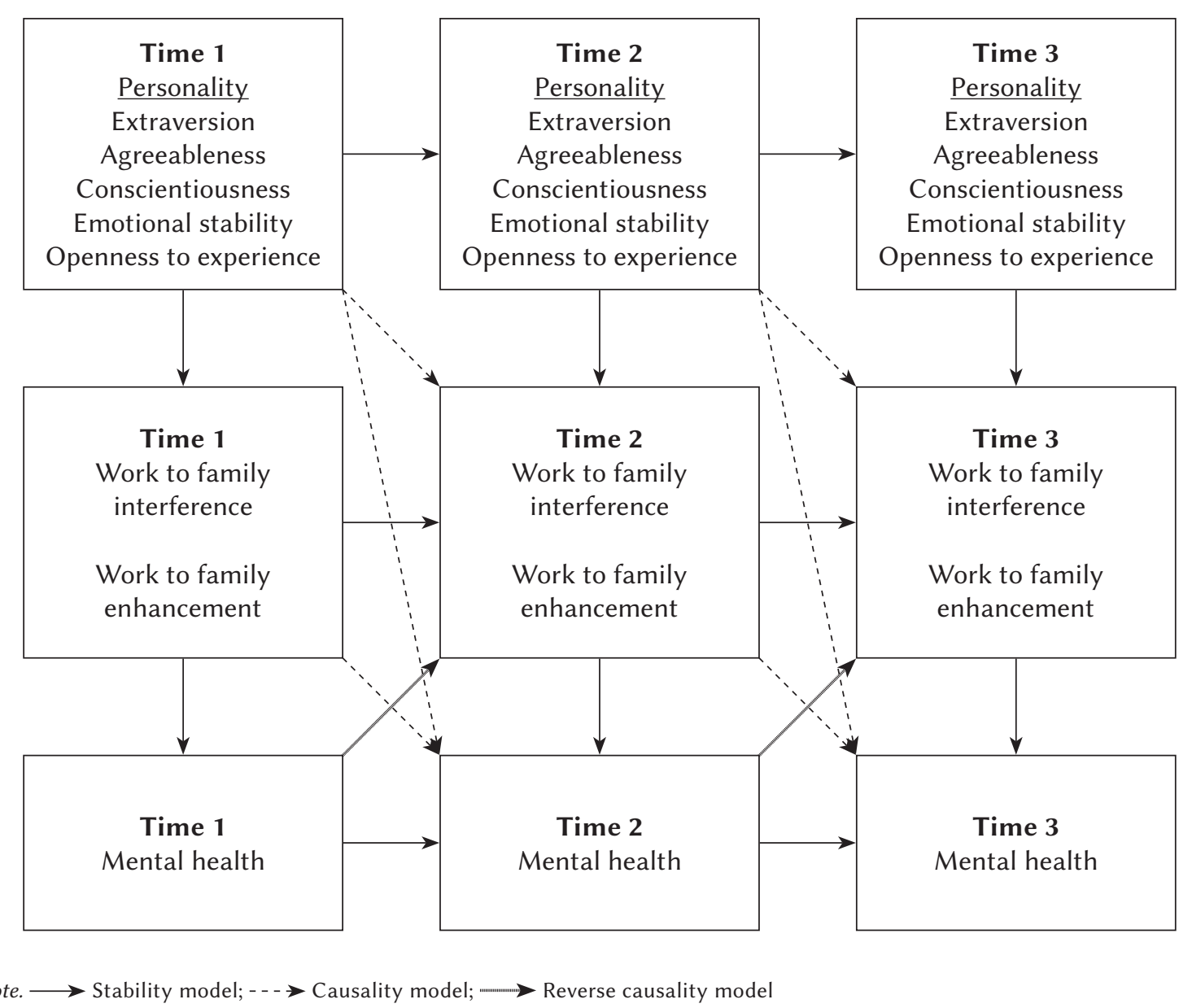

Figure 1. Hypothesized structural equation model.

\section{LONGITUDINAL STRUCTURAL MODELS}

As explained earlier, alternative longitudinal models were formed and compared by using chi-square difference tests. Table 2 indicates fit indices (as comparative fit index (CFI), standardized root-mean-square residual (SRMR) and root mean square error of approximation (RMSEA)) of each model and Table 3 indicates the chi-square difference scores $\left(\Delta \chi^{2}\right)$ between the compared models.

First, the stability models were compared with each other. The chi-square difference test $\left(\Delta \chi^{2}=2.1\right.$, $p=.881)$ revealed that the restricted model, which is stability model 2, was not significantly worse than the unrestricted model (stability model 1 ) with acceptable model fit $\left(\chi^{2} / d f=1.69, \mathrm{CFI}=0.93\right.$, SRMR $=0.06$, RMSEA $=0.03$ ). This shows the stability within the personality, work-family linkage and mental health constructs between all three waves (Cole \& Maxwell, 2003).

Second, the causality models were compared with each other and with stability model 2. In this case, these forward unidirectional paths test for relationships in the direction from personality to WFE/WFI linkage and from WFE/WFI to mental health. The com- parison of causality models revealed that the restricted model (causality model 2 ) had acceptable model fit $\left(\chi^{2} / d f=1.65, \mathrm{CFI}=0.94, \mathrm{SRMR}=0.06, \mathrm{RMSEA}=0.03\right)$ but was significantly worse $\left(\Delta \chi^{2}=15.7, p=.021\right)$ than the unrestricted model (causality model 1 ). This suggests that the constraints related to construct equivalence for paths from time 1 to time 2 and from time 2 to time 3 provided a statistically worse model than the unrestricted model. However, when we compared causality model 1 with stability model 2 , we found a significant improvement $\left(\Delta \chi^{2}=45.3, p=.026\right)$. Therefore, forward unidirectional paths significantly improve the model.

Thereafter the third models, which had same paths as the causality model but in a reverse direction, were compared with each other and with stability model 2 . The comparisons of reverse causality model 2 and reverse causality model 1 also indicated a significant chi square difference $\left(\Delta \chi^{2}=18.2, p=.034\right)$, which indicates that restricted reverse causality model 2 is significantly worse than reverse causality model 1 . This latter model had an acceptable model fit $\left(\chi^{2} / d f=1.66\right.$, $\mathrm{CFI}=0.94, \mathrm{SRMR}=0.06, \mathrm{RMSEA}=0.03)$ and showed significant improvement $\left(\Delta \chi^{2}=36.8, p=.037\right)$ in comparison to stability model 2 . 


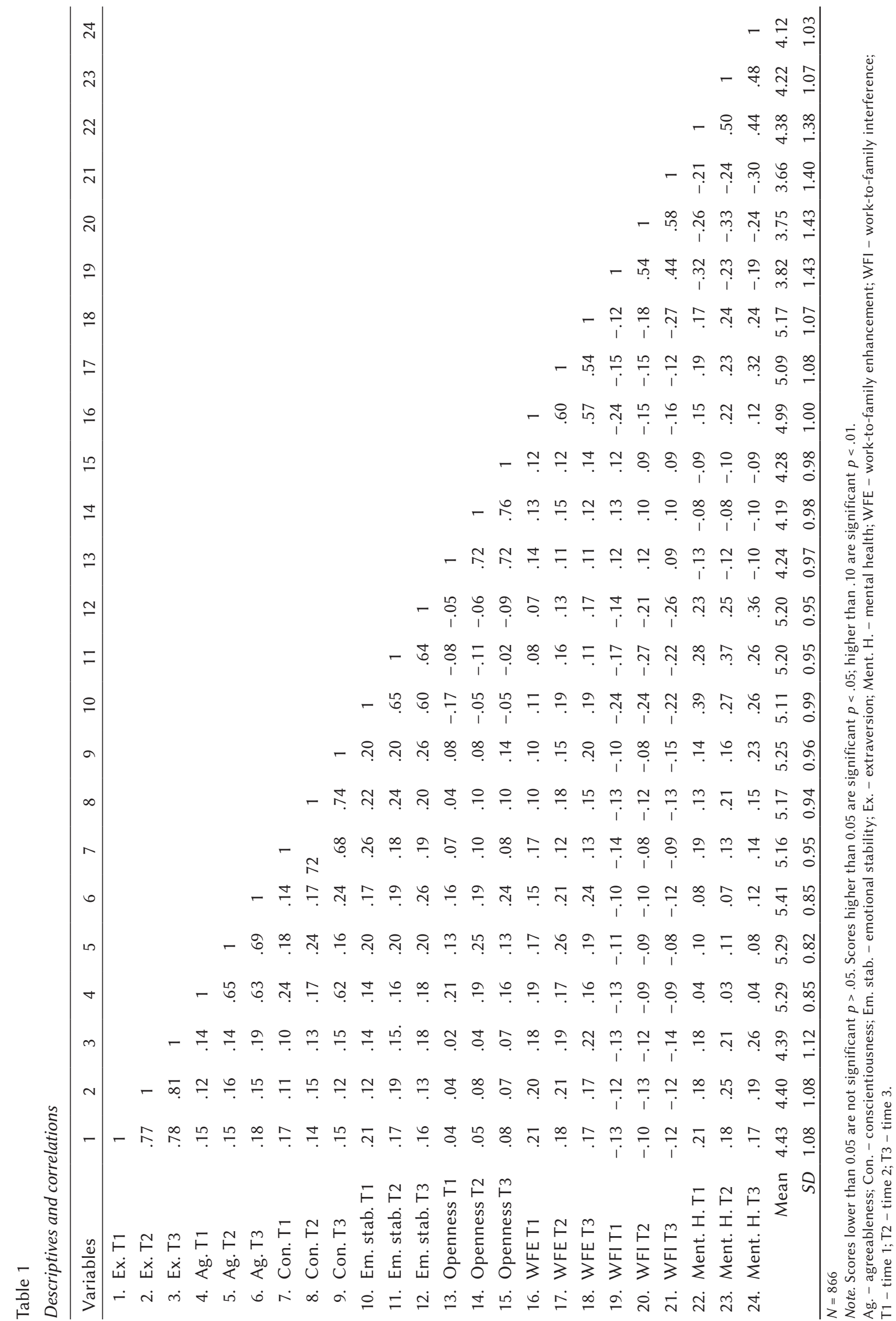


Table 2

Comparisons of stability, causality, reverse causality and reciprocal longitudinal models

\begin{tabular}{lcccc}
\hline Longitudinal models & $\chi^{2}$ & CFI & SRMR & RMSEA \\
\hline Model 1: Stability-1 & 171.2 & 0.93 & 0.07 & 0.04 \\
Model 2: Stability-2 & 169.1 & 0.93 & 0.07 & 0.04 \\
Model 3: Causality-1 & 123.8 & 0.93 & 0.06 & 0.03 \\
Model 4: Causality-2 & 139.5 & 0.94 & 0.06 & 0.03 \\
Model 5: Reverse causality-1 & 132.3 & 0.95 & 0.05 & 0.02 \\
Model 6: Reverse causality-2 & 150.5 & 0.95 & 0.05 & 0.02 \\
Model 7: Reciprocal-1 & 150.7 & 0.95 & 0.05 & 0.02 \\
\hline$N=866$
\end{tabular}

Note. $\mathrm{CFI}$ - comparative fit index; SRMR - standardized root mean squared residual; RMSEA - root mean square error of approximation; ${ }^{*} p<.05 ;{ }^{* *} p<.01$.

Table 3

Model comparisons

\begin{tabular}{lc}
\hline Model comparisons & $\Delta \chi^{2}$ \\
\hline Model 1 vs. Model 2 & 2.1 \\
Model 3 vs. Model 4 & $15.7^{*}$ \\
Model 2 vs. Model 3 & $45.3^{*}$ \\
Model 5 vs. Model 6 & $18.2^{*}$ \\
Model 2 vs. Model 5 & $36.8^{*}$ \\
Model 2 vs. Model 7 & $18.4^{*}$ \\
\hline N=866 & \\
Note. All $\chi^{2} / d f$ ratios $<2 ;{ }^{*} p<.05 ;{ }^{* *} p<.01$. &
\end{tabular}

Lastly, the combination of causality and reverse causality models was formed as a reciprocal model. Since in previous findings the restricted causality and reverse causality models were found to be statistically worse than unrestricted versions, the unrestricted reciprocal model was compared with stability model 2 . The chi-square difference showed that $\left(\Delta \chi^{2}=18.4\right.$, $p=.022)$ the reciprocal model produced significant improvement compared with stability model 2 . In a broader sense, for all variables stability within three times was obtained. However, findings on unidirectional and bidirectional relationships varied.

\section{FORWARD CROSS-LAGGED RELATIONSHIP OF PERSONALITY, WORK-TO-FAMILY INTERFERENCE/ENHANCEMENT AND MENTAL HEALTH}

The first finding in the forward unidirectional relationship was found between personality traits and workfamily enhancement. Conscientiousness $(\beta=.15$, $p<.01)$ and emotional stability $(\beta=.11, p<.01)$ at time 1 were found to be positively associated with work-to-family enhancement at time 2 , and conscientiousness $(\beta=.14, p<.01)$ and emotional stability $(\beta=.12, p<.01)$ at time 2 were found to be positively associated with work-to-family enhancement at time 3. However, conscientiousness at time 1 was found to be negatively associated with work-to-family interference at time $2(\beta=-.10, p<.05)$, whereas between time 2 and 3 a negative association was found between emotional stability (time 2) and work-to-family interference (time 3) $(\beta=-.12, p<.05)$. No longitudinal evidence was found between any personality traits and work-to-family interference. Altogether, these findings provide partial support for hypothesis 1 .

Turning to forward cross-lagged relations between work-family interference/enhancement and mental health, only work-to-family enhancement was found to be positively associated with mental health. Work-to-family enhancement at time 1 was found to be positively associated with mental health

Table 4

Sobel tests for forward and reverse cross-lagged paths

\begin{tabular}{lccc}
\hline Time 1 & Time 2 & Time 3 & $\begin{array}{c}\text { Sobel } \\
\text { test }(z)\end{array}$ \\
\hline Emotional stability & Work-to-family enhancement & Mental health & $3.18^{* *}$ \\
Work-to-family enhancement & Mental health & Work-to-family enhancement & $3.11^{* *}$ \\
\hline Note. ${ }^{*} p<.05 ;{ }^{* *} p<.01$. & &
\end{tabular}


at time $2(\beta=.15, p<.05)$, and work-to-family enhancement at time 2 was also found to be positively related to mental health at time $3(\beta=.22, p<.01)$. The findings revealed that work-to-family conflict at time 2 was only negatively associated with mental health at time $3(\beta=-.10, p<.01)$. However, a similar impact was not found between time 1 and time 2 $(\beta=-.01, p>.05)$. These results provide support for hypothesis $2 \mathrm{a}$ but not for hypothesis $2 \mathrm{~b}$.

Third, the findings also revealed the indirect effects of emotional stability on mental health via the mediator of work-to-family enhancement. Specifically, emotional stability at time 1 had a positive association with work-to-family enhancement at time 2 , which in turn had a positive association with mental health at time 3. In other words, higher reported emotional stability at time 1 was significantly associated with more work-to-family enhancement at time 2 , which, in turn, was associated with higher mental health at time 3. As suggested by Baron and Kenny (1986), the Sobel test was performed and the results are presented in Table 3. The finding confirmed the partial mediation effect of work-to-family enhancement between emotional stability and mental health $(z=3.18, p<.01)$.

\section{REVERSE CROSS-LAGGED RELATIONSHIP OF WORK-TO-FAMILY INTERFERENCE/ ENHANCEMENT AND MENTAL HEALTH}

In terms of the reverse paths, only the paths between mental health and work-to-family enhancement were found to be significant. Thus, mental health at time 1 $(\beta=.18, p<.05)$ was found to be significantly and positively associated with work-to-family enhancement at time 2 , which in turn $(\beta=.22, p<.01)$ was positively associated mental health at time 3 . The Sobel test also confirmed the significance of this indirect effect $(z=3.11, p<.01)$. The forward relation of emotional stability to work-to-family enhancement and to mental health was not found in reverse paths. Also, there are no statistically significant paths regarding mental health to work-to-family interference or work-to-family interference to any personality traits.

\section{DISCUSSION}

In this section, we discuss the contributions and limitations of the study. We also suggest avenues for further research.

\section{CONTRIBUTION TO THE LITERATURE}

This study was conducted to examine relationships between personality, work-to-family interference/ enhancement and mental health in a three-wave longitudinal design. The findings extend the literature in several ways. First, the time effects on each of the eight variables were tested and the results indicate a significant time impact on agreeableness. Agreeableness is considered as prosocial behavior and is closely related to sociocognitive capabilities of individuals. Bergeman et al. (1993) revealed that the environmental parameters' impact on agreeableness is higher than the genetic influence, when it is compared with openness to experience and conscientiousness. Although moderate stability of agreeableness after the preschool years was obtained in previous research (Graziano \& Eisenberg, 1997), the social interactions, shared, family-wide environmental experiences also represent a significant part of the agreeableness and its stability across time and situations (Caspi, Roberts, \& Shiner, 2005).

Then the relationships between personality traits and work-to-family interference/enhancement were analyzed and the results indicate that conscientiousness and emotional stability are positively associated with work-to-family enhancement over time. This shows consistency with the findings of Wayne et al. (2004); however, the longitudinal approach of this study also provides more comprehensive views through personality traits and work-family relations. Conscientious individuals are hardworking, wellorganized and efficient in time management (Barrick \& Mount, 1991). Since they are also achievement oriented, work demands and tasks that they finished correctly and on time stimulate their performance related to family roles. Moreover, individuals with high emotional stability scores may be more able to perceive beneficial impacts of working on their family responsibilities. As such, they can take advantage of having multiple roles and using interpersonal skills gained from work to improve the quality and performance (Hurtz \& Donovan, 2000). Although these two personality traits were found to be negatively associated with work-family conflict in past research (Wayne et al., 2004), this longitudinal study contributes to the literature by highlighting their impact on work-to-family enhancement in the long term.

Contrary to the findings of Rantanen et al. (2005), we found no relationship between emotional stability and work-to-family interference over time. However, it is important to note that our cross-sectional findings revealed a significant positive relationship between emotional stability and work-to-family interference in all three waves. As Soldz and Vaillant (1999) suggested, stage of life and the time lags in longitudinal studies are important when examining the impact of personality traits on any outcomes. Hence, further longitudinal studies with different time lags and different designs (with mediators and moderators) may shed some light on the impact of emotional stability on work-to-family conflict over time. 
Third, work-family enhancement, which means positive impacts of work on the quality of an individual's home life, was found to be positively related to mental health through three waves. Individuals who perceive a stimulating effect of work on family responsibilities are more able to balance work and family domains, which in turn enhances their mental health over time. The positive relationships between work-to-family enhancement and mental health are consistent with role accumulation theory (Sieber, 1974). Having multiple roles can be more beneficial than harmful, and there is work-family enrichment because the transfer of different sorts of resources (i.e., affects, skills, values and developmental gains) and positive spillover between work and family domains (Grzywacz \& Marks, 2000). For example, family members can provide affection and social support, which can help people to deal with stressful situations at work and vice versa. It is not only the number of roles but also the subjective feelings of individuals on rewarding aspects of the roles that can potentially increase wellbeing. Work-family enhancement can induce a set of social activities and tasks that improve functioning, produce more energy and increase commitment and wellbeing (Grzywacz, 2000).

Fourth, and most importantly, this study showed the longitudinal mediating role of work-family enhancement between emotional stability and mental health. To a large extent, the impact of emotional stability on mental health was indirect, through perceptions of work-family enhancement. These findings demonstrated that emotional stability predict and shape the perceptions of multiple roles and the interpretation of work demands that can stimulate individuals' mental health over time. To our knowledge, no previous study has examined the linkage between emotional stability, work-family enhancement and mental health longitudinally. In other words, individuals who have emotional stability perceive work with its positive aspects and it promotes positive moods that are useful for their mental health (Kinnunen et al., 2006; McNall et al., 2010).

It is also important to note that work-family enhancement did not fully mediate the emotional stability and mental health relationship; in other words, emotional stability also has a direct positive relationship with mental health that is independent of individuals' perceptions on work-to-family enhancement. This is not surprising since emotionally stable individuals typically have effective coping mechanisms to deal with stress and they are able to keep calm. They can balance their emotional shifts and they generally tend not to be moody or overly sensitive (Brebner, 2001). Understanding the positive association between emotional stability and mental health of employees helps managers to offer some personal development programs. Crucially, our findings suggest that one of the mechanisms underlying the emotional stability and mental health process is the improvement of work-to-family enhancement over time.

Last but not least, this study is the first to consider the reciprocal relationship of work-family experiences and mental health. The results related to direct reciprocal associations revealed that mental health at time 1 was positively related to family enhancement at time 2, which in turn was positively associated with mental health at time 3 . This process may be explained by the conservation of resource theory, which posits that resources are intertwined and play a critical role in stress and wellbeing (Hobfoll, 1989). Although the relatedness of resources has generally been discussed from a resource-loss perspective, the reverse is also possible. Our findings suggest that individuals' high mental health improves their work-family enhancements and that, simultaneously, work-family enhancement stimulates individuals' mental health. This reciprocal relationship of workfamily enhancement and mental health has important implications for workplace support for workers. Counseling and family therapy, family-friendly policies and some other psychotherapy programs would be beneficial for employees in enhancing their mental health and work-family balance. Furthermore, the strength-based approach, in other words positive psychotherapy, that focuses on and emphasizes positive resources of individuals (Berg-Weger, Rubio, \& Tebb, 2001) can be used in improving employees' work and family roles' interactions. Intensification of positive emotions, relationships and values of work would be valuable for individuals' mental health and family reciprocally.

As a result, beyond merely replicating previous longitudinal findings (Rantanen et al., 2005), our findings are the first to confirm the partial mediation role of work-to-family enhancement between emotional stability and mental health, and bidirectional relations of work-to-family enhancement and mental health. There are no statistically significant paths regarding mental health to work-to-family interference or work-to-family interference to any personality traits. Since the longitudinal stability of these personality traits after age 30 has been reported in many studies (Costa \& McCrae, 1988; McCrae \& Costa, 1994; Roberts \& DelVecchio, 2000), it is not surprising not to have any reciprocal impacts from work-family experiences and mental health to personality traits.

This study also contributes to Australian workplace culture. Work-family conflict is a widely studied concept in Australia. Fujimoto, Azmat, and Härtel (2013) reported that the work-family balance of workers in Australia is much more related to workrelated matters such as working hours, managers support, hour mismatch and job context (Reynolds \& Aletraris, 2007). However, this study examines the work-family interference and enhancement with individual related factors (personality traits and mental 
health). Moreover, we may offer some suggestions that are specific to that country. Previous studies revealed that part-time work is more common among women in Australia. In other words, women want to decrease their working time in order to meet family demands. However, the findings of this study suggest that some human resource practices, which may be influential for individuals' personal development, may help workers to cope with work-to-family interference and enhance work-to-family enhancement.

\section{LIMITATIONS AND SUGGESTIONS FOR FUTURE RESEARCH}

Although the present study provided a large, longitudinal and nationally representative sample that increases the generalizability of these findings, there are several limitations. First, although longitudinal studies provide a stronger test of causality than do cross-sectional studies, further longitudinal experimental studies would confirm the cause-effect relationship between personality traits, work-family interactions and mental health. Even so, this study helped to demonstrate the antecedent-outcome relations longitudinally by measuring every concept at each time point and considering the stability and cross-lagged relations between them.

Second, despite the lack of guidelines in appropriate time lag selection in longitudinal studies (Zapf, Dormann, \& Frese, 1996), further studies with different time lengths could better capture the relations that were missed in this study. Third, the use of repeated measures and self-reported data increases the possibility of common method variance (Podsakoff, MacKenzie, Lee, \& Podsakoff, 2003). Further research might solve this problem by using other data collection methods with self-reporting. In addition, the nature of the relationship between work and family life appears multidirectional and complex. Thus, there is a need to investigate the overlap between work and family from different perspectives, for example, studying family-to-work (rather than workto-family) conflict and enhancement in order to gain some insight into the antecedents and consequences of work-family outcomes such as life satisfaction or health.

\section{ReferenCES}

Abdi, H. (2003). Factor rotations in factor analyses. In M. Lewis-Beck, A. Bryman, \& T. Futing (Eds.), Encyclopedia of Social Sciences Research Methods (pp. 792-795). Thousand Oaks, CA: Sage.

Allen, T., Herst, D., Bruck, C., \& Sutton, M. (2000). Consequences associated with work to family conflict: A review and agenda for future research. Journal of
Occupational Health Psychology, 5, 278-308. https:// doi.org/10.1037/1076-8998.5.2.278

Argyle, M., \& Lu, L. (1990). The happiness of extraverts. Personality and Individual Differences, 11, 1011-1017. https://doi.org/10.1016/0191-8869(90)90128-E

Baltes, B. B., Zhdanova, L. S., \& Clark, M. A. (2011). Examining the relationships between personality, coping strategies, and work-family conflict. Journal of Business and Psychology, 26, 517-530. https://doi.org/10.1007/s10869-010-9207-0

Baron, R. M., \& Kenny, D. A. (1986). The moderator-mediator variable distinction in social psychological research: Conceptual, strategic and statistical considerations. Journal of Personality and Social Psychology, 51, 1173-1182. https://doi. org/10.1037/0022-3514.51.6.1173

Barrick, M. R., \& Mount, M. K. (1991). The Big Five personality dimensions and job performance: A meta-analysis. Personnel Psychology, 44, 1-26. https://doi.org/10.1111/j.1744-6570.1991.tb00688.x

Bergeman, C. S., Chlpuer, H. M., Plomin, R., Pedersen, N. L., McClearn, G. E., Nesselroade, J. R., Costa, P. T., \& McCrae, R. R. (1993). Genetic and environmental effects on openness to experience, agreeableness, and conscientiousness: An adoption/twin study. Journal of Personality, 61, 159-179. https://doi.org/10.1111/j.1467-6494.1993.tb01030.x

Berg-Weger, M., Rubio, D., \& Tebb, S. (2001). Strengthsbased practice with family caregivers of the chronically ill: Qualitative insights. Families in Society, 82, 263-272. https://doi.org/10.1606/1044-3894.191

Berkowitz, L. (1990). On the formation and regulation of anger and aggression: A cognitive-neoassociationistic analysis. American Psychologist, 45, 494503. https://doi.org/10.1037/0003-066X.45.4.494

Brebner, J. (2001). Personality and stress coping. Personality and Individual Differences, 31, 317-327. https://doi.org/10.1016/S0191-8869(00)00138-0

Brebner, J., Donaldson, J., Kirby, N., \& Ward, L. (1995). Relationships between happiness and personality. Personality and Individual Differences, 19, 251-258. https://doi.org/10.1016/0191-8869(95)00022-X

Breslin, F. C., \& Mustard, C. (2003). Factors influencing the impact of unemployment on mental health among young and older adults in a longitudinal, population-based survey. Scandinavian Journal of Work, Environment \& Health, 29, 5-14. https://doi. org/10.5271/sjweh.698

Byrne, B. M., Shavelson, R. J., \& Muthén, B. (1989). Testing for the equivalence of factor covariance and mean structures: The issue of partial measurement invariance. Psychological Bulletin, 105, 456466. https://doi.org/10.1037/0033-2909.105.3.456

Casper, W. J., Eby, L. T., Bordeaux, C., Lockwood, A., \& Lambert, D. (2007). A review of research methods in IO/OB work-family research. Journal of Applied Psychology, 92, 28-43. https://doi.org/10.1037/00219010.92.1.28 
Casper, W. J., Harris, C., Taylor-Bianco, A., \& Wayne, J. H. (2011). Work-family conflict, perceived supervisor support and organizational commitment among Brazilian professionals. Journal of Vocational Behavior, 79, 640-652. https://doi.org/10.1016/j. jvb.2011.04.011

Casper, W. J., De Hauw, S., \& Wayne, J. H. (2013). Concepts and measures in the work-family interface: Implications for work-family integration. In D. A. Major \& R. Burke (Eds.), Handbook of work-life integration among professionals: Challenges and opportunities (pp. 35-57). Northampton, MA: Edward Elgar Publishing.

Caspi, A., Roberts, B. W., \& Shiner, R. L. (2005). Personality development: Stability and change. Annual Review of Psychology, 56, 453-484. https://doi. org/10.1146/annurev.psych.55.090902.141913

Cheng, H., \& Furnham, A. (2001). Attributional style and personality as predictors of happiness and mental health. Journal of Happiness Studies, 2, 307-327. https://doi.org/10.1023/A:1011824616061

Cho, E., \& Tay, L. (2016). Domain satisfaction as a mediator of the relationship between work-family spillover and subjective well-being: a longitudinal study. Journal of Business and Psychology, 31, 445457. https://doi.org/10.1007/s10869-015-9423-8

Clark, L. A., \& Watson, D. (1991). General affective dispositions in physical and psychological health. In C. R. Snyder \& D. R. Forsyth (Eds.), Handbook of social and clinical psychology: The health perspective (pp. 224-245). New York: Pergamon Press.

Cole, D. A., \& Maxwell, S. E. (2003). Testing mediational models with longitudinal data: questions and tips in the use of structural equation modeling. Journal of Abnormal Psychology, 112, 558-577. https://doi.org/10.1037/0021-843X.112.4.558

Costa, P. T., \& McCrae, R. R. (1980). Influence of extraversion and neuroticism on subjective well-being: Happy and unhappy people. Journal of Personality and Social Psychology, 38, 668-678. https://doi. org/10.1037/0022-3514.38.4.668

Costa, P. T., \& McCrae, R. R. (1988). Personality in adulthood: a six-year longitudinal study of self-reports and spouse ratings on the NEO Personality Inventory. Journal of Personality and Social Psychology, 54, 853-863. https://doi.org/10.1037//0022-3514.54.5.853

Costa, P. T., McCrae, R. R., \& Dye, D. (1991). Facet scales for agreeableness and conscientiousness: A revision of the NEO Personality Inventory. Personality and Individual Differences, 12, 887-898. https://doi.org/10.1016/0191-8869(91)90177-D

DeNeve, K., \& Cooper, H. (1998). The happy personality: A meta-analysis of 137 personality traits and subjective well-being. Psychological Bulletin, 124, 197-229. https://doi.org/10.1037/0033-2909.124.2.197

Edwards, J. R., \& Rothbard, N. P. (2000). Mechanisms linking work and family: Clarifying the relationship between work and family constructs. Acad- emy of Management Review, 25, 178-199. https:// doi.org/10.2307/259269

Fang, R., Landis, B., Zhang, Z., Anderson, M. H., Shaw, J. D., \& Kilduff, M. (2015). Integrating personality and social networks: A meta-analysis of personality, network position, and work outcomes in organizations. Organization Science, 26, 12431260. https://doi.org/10.1287/orsc.2015.0972

Feldt, T., Metsapelto, R. L., Kinnunen, U., \& Pulkkinen, L. (2007). Sense of coherence and five-factor approach to personality. European Psychologist, 12, 165-172. https://doi.org/10.1027/1016-9040.12.3.165

Frijters, P., Johnston, D. W., \& Shields, M. A. (2014). The effect of mental health on employment: Evidence from Australian panel data. Health Economics, 23, 1058-1071. https://doi.org/10.1002/hec.3083

Frone, M. R., Russell, M., \& Cooper, M. L. (1992). Antecedents and outcomes of work-family conflict: Testing a model of the work-family interface. Journal of Applied Psychology, 77, 65-78. https://doi. org/10.1037/0021-9010.77.1.65

Frone, R. M., Russell, M., \& Cooper, M. L. (1997). Relation of work-family conflict to health outcomes: A four-year longitudinal study of employed parents. Journal of Occupational and Organizational Psychology, 70, 325-335. https://doi. org/10.1111/j.2044-8325.1997.tb00652.x

Frye, N. K., \& Breaugh, J. A. (2004). Family-friendly policies, supervisor support, work-family conflict, family-work conflict, and satisfaction: A test of a conceptual model. Journal of Business and Psychology, 19, 197-220. https://doi.org/10.1007/s10869004-0548-4

Fujimoto, Y., Azmat, F., \& Härtel, C. E. (2013). Gender perceptions of work-life balance: Management implications for full-time employees in Australia. Australian Journal of Management, 38, 147-170. https://doi.org/10.1177/0312896212449828

Furnham, A., \& Cheng, H. (1999). Personality as predictor of mental health and happiness in the East and West. Personality and Individual Differences, 27, 395-403. https://doi.org/10.1016/S01918869(98)00250-5

Goldberg, L. R. (1993). The structure of phenotypic personality traits. American Psychologist, 48, 2634. https://doi.org/10.1037//0003-066x.48.1.26

Goode, A., \& Watson N. (Eds.) (2007) HILDA User Manual - Release 5.0. Melbourne: Melbourne Institute of Applied Economic and Social Research, University of Melbourne.

Goodwin, R. D., \& Friedman, H. S. (2006). Health status and the five-factor personality traits in a nationally representative sample. Journal of Health Psychology, 11, 643-654. https://doi.org/10.1177/ 1359105306066610

Graziano, W. G., \& Eisenberg, N. (1997). Agreeableness: A dimension of personality. In R. Hogan, J. A. Johnson, \& S. R. Briggs (Eds.), Handbook of personality 
psychology (pp. 795-824). San Diego, CA: Academic Press.

Greenhaus, J. H., \& Beutell, N. J. (1985). Sources of conflict between work and family roles. Academy of Management Review, 10, 76-88. https://doi. org/10.2307/258214

Grzywacz, J. (2000). Work-family spillover and health during midlife: Is managing conflict everything? American Journal of Health Promotion, 14, 236243. https://doi.org/10.4278/0890-1171-14.4.236

Grzywacz, J. G., \& Marks, N. F. (2000). Reconceptualizing the work-family interface: An ecological perspective on the correlates of positive and negative spillover between work and family. Journal of Occupational Health Psychology, 5, 111-126. https:// doi.org/10.1037/1076-8998.5.1.111

Haslam, N., Whelan, J., \& Bastian, B. (2009). Big five traits mediate associations between values and subjective well-being. Personality and Individual Differences, 46, 40-42. https://doi.org/10.1016/j. paid.2008.09.001

Hobfoll, S. E. (1989). Conservation of resources: A new attempt at conceptualizing stress. American Psychologist, 44, 513-524. https://doi.org/10.1037//0003066x.44.3.513

Hu, L. T., \& Bentler, P. M. (1999). Cutoff criteria for fit indexes in covariance structure analysis: Conventional criteria versus new alternatives. Structural Equation Modeling: A Multidisciplinary Journal, 6, 1-55. https://doi.org/10.1080/10705519909540118

Hurtz, G. M., \& Donovan, J. J. (2000). Personality and job performance: The Big Five revisited. Journal of Applied Psychology, 85, 869-879. https://doi. org/10.1037/0021-9010.85.6.869

Judge, T. A., Heller, D., \& Mount, M. K. (2002). Five-factor model of personality and job satisfaction: a meta-analysis. Journal of Applied Psychology, 87, 530541. https://doi.org/10.1037/0021-9010.87.3.530

Judge, T. A., Higgins, C. A., Thoresen, C. J., \& Barrick, M. R. (1999). The Big-Five personality traits, general ability, and career success across the life span. Personnel Psychology, 52, 621-652. https://doi. org/10.1111/j.1744-6570.1999.tb00174.x

Judge, T. A., \& Ilies, R. (2002). Relationship of personality to performance motivation: A meta-analytic review. Journal of Applied Psychology, 87, 797-807. https://doi.org/10.1037/0021-9010.87.4.797

Kinnunen, U., Feldt, T., Geurts, S., \& Pulkkinnen, L. (2006). Types of work-family interface: Well-being correlates of negative and positive spillover between work and family. Scandinavian Journal of Psychology, 47, 149-162. https://doi.org/10.1111/j.14679450.2006.00502.x

Kinnunen, U., Vermulst, A., Gerris, J., \& Makikangas A. (2003). Work-family conflict and its relations to wellbeing: The role of personality as a moderating factor. Personality and Individual Differences, 35, 16691683. https://doi.org/10.1016/S0191-8869(02)00389-6
Kossek, E., Noe, R., \& DeMarr, B. (1999). Work-family role synthesis: Individual and organizational determinants. International Journal of Conflict Management, 10, 102-129. https://doi.org/10.1108/eb022820

Kotov, R., Gamez, W., Schmidt, F., \& Watson, D. (2010). Linking "big" personality traits to anxiety, depressive, and substance use disorders: A meta-analysis. Psychological Bulletin, 136, 768-821. https://doi.org/10.1037/a0020327

Losoncz, I. (2009). Personality traits in HILDA. Australian Social Policy, 8, 169-198.

Losoncz, I., \& Bortoiotto, N. (2009). Work-life balance: The experiences of Australian working mothers. Journal of Family Studies, 15, 122-138. https://doi. org/10.5172/jfs.15.2.122

Marshall, N. L., \& Barnett, R. C. (1993). Work-family strains and gains among two-earner couples. Journal of Community Psychology, 21, 64-78. https:// doi.org/10.1002/1520-6629(199301)21:1<64::AIDJCOP2290210108>3.0.CO;2-P

Matzler, K., \& Renzl, B. (2007). Personality traits, employee satisfaction and affective commitment. Total Quality Management, 18, 589-598. https:// doi.org/10.1080/14783360601061528

McCrae, R. R., \& Costa, P. T. (1991). Adding Liebe und Arbeit: The full five-factor model and well-being. Personality and Social Psychology Bulletin, 17, 227232. https://doi.org/10.1177/014616729101700217

McCrae, R. R., \& Costa, P. T. (1994). The stability of personality: Observations and evaluations. Current Directions in Psychological Science, 3, 173-175. https://doi.org/10.1111/1467-8721.ep10770693

McCrae, R. R., \& Costa, P. T. (2008). The five-factor theory of personality. In O. P. John, R. W. Robins, \& L. A. Pervin (Eds.), Handbook of personality: Theory and research (pp. 159-181). New York: Guilford Press.

McCrae, R. R., \& John, O. P. (1992). An introduction to the five-factor model and its applications. Journal of Personality, 60, 175-215. https://doi. org/10.1111/j.1467-6494.1992.tb00970.x

McNall, L. A., Nicklin, J. M., \& Masuda, A. D. (2010). A meta-analytic review of the consequences associated with work-family enrichment. Journal of Business and Psychology, 25, 381-396. https://doi. org/10.1007/s10869-009-9141-1

Mesmer-Magnus, J., \& Viswesvaran, C. (2005). Convergence between measures of work to family and family to work conflict: A meta-analytic examination. Journal of Vocational Behavior, 67, 215-232. https://doi.org/10.1016/j.jvb.2004.05.004

Murphy, G. C., \& Athanasou, J. A. (1999). The effect of unemployment on mental health. Journal of Occupational and Organizational Psychology, 72, 83-99. https://doi.org/10.1348/096317999166518

Odle-Dusseau, H. N., Britt, T. W., \& Bobko, P. (2012). Work-family balance, well-being, and organizational outcomes: Investigating actual versus de- 
sired work/family time discrepancies. Journal of Business and Psychology, 27, 331-343. https://doi. org/10.1007/s10869-011-9246-1

Penley, J. A., \& Tomaka, J. (2002). Association among the Big Five, emotional responses, and coping with acute stress. Personality and Individual Differences, 32, 1215-1228. https://doi.org/10.1016/ S0191-8869(01)00087-3

Pittenger, D. J. (2004). The limitations of extracting typologies from trait measures of personality. Personality and Individual Differences, 37, 779-787. https://doi.org/10.1016/j.paid.2003.10.006

Podsakoff, P. M., MacKenzie, S. B., Lee, J. Y., \& Podsakoff, N. P. (2003). Common method biases in behavioral research: a critical review of the literature and recommended remedies. Journal of Applied Psychology, 88, 879-903. https://doi.org/10.1037/00219010.88.5.879

Rantanen, J., Pulkkinen, L., \& Kinnunen, U. (2005). The Big Five personality dimensions, work-family conflict, and psychological distress: A longitudinal view. Journal of Individual Differences, 26, 155166. https://doi.org/10.1027/1614-0001.26.3.155

Reynolds, J., \& Aletraris, L. (2007). Work-family conflict, children, and hour mismatches in Australia. Journal of Family Issues, 28, 749-772. https://doi. org/10.1177/0192513X06296634

Roberts, B. W., \& DelVecchio, W. F. (2000). The rankorder consistency of personality traits from childhood to old age: a quantitative review of longitudinal studies. Psychological Bulletin, 126, 3-25. https://doi.org/10.1037/0033-2909.126.1.3

Roccas, S., Sagiv, L., Schwartz, S. H., \& Knafo, A. (2002). The Big Five personality factors and personal values. Personality and Social Psychology Bulletin, 28, 789-801. https://doi.org/10.1177/0146167202289008

Saucier, G. (1994). Mini-markers: A brief version of Goldberg's Big-Five markers. Journal of Personality Assessment, 63, 506-516. https://doi.org/10.1207/ s15327752jpa6303_8

Schacter, D. L., Gilbert, D. T., \& Wegner, D. M. (2009). Psychology (2nd ed.). New York: Worth Publishers.

Schieman, S., \& Glavin, P. (2011). Education and work-family conflict: Explanations, contingencies and mental health consequences. Social Forces, 89, 1341-1362. https://doi.org/10.1093/sf/89.4.1341

Shirazi, M., Khan, M. A., \& Ansari, M. F. A. (2013). Mental health in relation to personality characteristics among professional and non-professional students. Journal of Arts, Science and Commerce, 1, 105-114.

Sieber, S. D. (1974). Toward a theory of role accumulation. American Sociological Review, 39, 567-578. https://doi.org/10.2307/2094422

Sobel, M. E. (1982). Asymptotic confidence intervals for indirect effects in structural equations models. In S. Leinhart (Ed.), Sociological Methodology (pp. 290-312). San Francisco, CA: Jossey-Bass.
Soldz, S., \& Vaillant, G. E. (1999). The Big Five personality traits and the life course: A 45-year longitudinal study. Journal of Research in Personality, 33, 208-232. https://doi.org/10.1006/jrpe.1999.2243

Tan, M. (2007). The effects of family cohesion and personality on the mental health of young Australians. Preliminary draft. Retrieved from https:// melbourneinstitute.unimelb.edu.au/assets/documents/hilda-bibliography/hilda-conference-papers/2007/Tan,-Michelle_final-paper.pdf

Vollrath, M., \& Torgersen, S. (2000). Personality types and coping. Personality and Individual Differences, 29, 367-378. https://doi.org/10.1016/S01918869(99)00199-3

Watson, D., \& Clark, L. A. (1992). On traits and temperament: General and specific factors of emotional experience and their relation to the fivefactor model. Journal of Personality, 60, 441-476. https://doi.org/10.1111/j.1467-6494.1992.tb00980.x

Watson, D., \& Hubbard, B. (1996). Adaptational style and dispositional structure: Coping in the context of the five-factor model. Journal of Personality, 64, 735-774. https://doi.org/10.1111/j.1467-6494.1996. tb00943.x

Wayne, J. H., Musisca, N., \& Fleeson, W. (2004). Considering the role of personality in the workfamily experience: Relationship of the big five to work-family conflict and facilitation. Journal of Vocational Behavior, 64, 108-130. https://doi. org/10.1016/S0001-8791(03)00035-6

World Health Organization (WHO). (2005). Promoting mental health: Concepts, emerging evidence, practice. Geneva: World Health Organization.

World Health Organization (WHO). (2006). Economic aspects of mental health: Key messages to health planners and policy makers. Technical report. Geneva: World Health Organization.

World Health Organization (WHO). (2013), Investing in mental health: Evidence for action. Geneva: World Health Organization.

Zapf, D., Dormann, C., \& Frese, M. (1996). Longitudinal studies in organizational stress research: a review of the literature with reference to methodological issues. Journal of Occupational Health Psychology, 1, 145-169. https://doi.org/10.1037//1076-8998.1.2.145 